\title{
Introducción
}

\section{Visiones de San Martín y territorios vividos en la Amazonía andina}

\section{Valeria Biffi}

https://orcid.org/0000-0003-3039-084X

London School of Economics

vbiffi@pucp.edu.pe

\section{Anahí Chaparro \\ (iD) https://doi.org/0000-0001-7321-4307 \\ Universidad Federal de Río de Janeiro \\ Centro Amazónico de Antropología y Aplicación Práctica \\ anahichaparro@gmail.com}

En tanto concepto polisémico, el territorio ha ganado cada vez más espacio en la discusión antropológica. En la Amazonía, esto ha estado vinculado tanto a la importancia que le ha dado el movimiento indígena como eje de su lucha como al interés por reflexionar sobre la gobernanza de los recursos naturales. El caso de la región San Martín es particular debido a las importantes transformaciones políticas, económicas, sociales y ambientales que ha atravesado en las últimas décadas y a la apuesta por un enfoque territorial en la gestión pública —usado de modelo para políticas nacionales - que ha puesto en evidencia diferentes formas en las que distintos actores se vinculan, imaginan y planifican el futuro en relación con su entorno. La iniciativa para el presente número parte de las reflexiones conjuntas en el marco del evento «Visiones de San Martín. Debate sobre el territorio regional con las ciencias sociales», realizado en la Universidad Nacional de San Martín, en julio de 2019. En este taller, se presentaron versiones preliminares de varios de los artículos aquí reunidos. Agradecemos a los distintos ponentes y comentaristas que contribuyeron con este esfuerzo, incluido a quienes no pudieron participar en este número, así como a las instituciones que apoyaron su organización. 
El territorio que hoy en día conocemos como la región San Martín ha pasado por continuos procesos de cambio vinculados con ciclos económicos y de colonización, impulsados por políticas desarrollistas, transformando los modos de vida locales, sobre todo el de la población rural e indígena. Un hito central en las últimas décadas fue la apertura de la carretera Fernando Belaunde Terry, que intensificó la articulación del mercado regional hacia la costa y la expansión de los monocultivos - incluido el de la coca - en detrimento de los bosques.

Con el proceso de descentralización, la década de 2000 estuvo marcada por una política regional que apostó por la conservación a través de distintos mecanismos que, en varios casos, implicaron la expropiación de territorios indígenas y la criminalización de sus actividades. Al mismo tiempo, por un lado, se promovió el cultivo de productos destinados a la exportación, como el café y el cacao, como ejes de una economía regional post coca y del desarrollo rural, con enfoque de comercio justo para pequeños productores rurales e indígenas, con el fin de mitigar los impactos de la degradación ambiental. Por el otro, se incentivó el (mono)cultivo de palma aceitera, vinculado con el acaparamiento de tierras y la deforestación por la ampliación de la frontera agrícola. A esto se ha sumado el avance de la extracción ilegal y tráfico de madera. En este contexto, mecanismos como la zonificación, el ordenamiento territorial y la retribución por servicios ecosistémicos han sido centrales en la discusión sobre el gobierno de los recursos naturales y de la población. En ese marco, también se ha incrementado el reconocimiento de comunidades nativas y de su organización en federaciones, no sin cuestionamientos por autoridades y funcionarios públicos. Así, la indigeneidad se ha convertido también en un campo de disputa dentro de la gobernanza territorial.

La demarcación de estas fronteras territoriales e identitarias coexiste, transforma y es transformada por las redes y flujos que las atraviesan: la relación entre la población indígena y el Estado, las reflexiones sobre indigeneidad en las comunidades nativas, la circulación de distintos conocimientos y de la población, las relaciones de parentesco y amistad que facilitan el acceso al territorio y a distintas oportunidades, los ciclos de regeneración de la vida y las relaciones entre humanos y no humanos. Estas dinámicas ponen en juego distintas nociones de lo que podemos traducir como territorio, vida, naturaleza, conocimiento, gobierno y Estado. Los diferentes artículos de esta edición de Anthropologica, mayoritariamente etnográficos, analizan el modo en que estas nociones y experiencias modelan a San Martín en tanto región, así como a los sujetos que la habitan y sus relaciones. Estos exploran, especialmente, las (des)conexiones entre las miradas estatales e indígeno-campesinas en y respecto de la región. 
Todos los artículos de este número han coincidido en compartir reflexiones de investigaciones que involucran a la población kichwa de San Martín. Esta focalización, al mismo tiempo que circunscribe la reflexión - sin pretender con ello agotar las miradas sobre la región-, muestra la diversidad de ángulos desde los que se puede pensar la relación de esta población con su entorno, con los llamados mestizos, con el Estado y con la sociedad en general. Asimismo, las contribuciones a la convocatoria abordan arenas en las que los kichwa negocian estas relaciones dentro de distintas formas de gobierno, como las que definen y ponen en ejecución modos de propiedad, derechos culturales y políticas de gestión ambiental. Además, varias problematizan también cómo las relaciones que se tejen en estos procesos constituyen modos de territorialización vinculados con prácticas diferenciadas de conocimiento, ya sea el de las llamadas ciencias exactas (como la ecología, la biología, la agronomía o la genética), las de la gestión pública o las de los modos de crianza kichwa, a las que se pueden sumar los saberes antropológicos expuestos en estos artículos como parte de un ejercicio de discusión con otros actores de la región.

Valeria Biffi explora la mirada indígena sobre el Estado a partir de la implementación del Programa Nacional de Conservación de Bosques (PNCB) del Ministerio del Ambiente. La autora discute como la presencia de este programa genera una débil conexión del Estado como institución ambiental, pero refuerza la mirada indígena del Estado como proveedor de desarrollo. No obstante, la población indígena ha construido interpretaciones alternativas a la conservación del bosque como capital que atrae nuevas oportunidades de desarrollo y de los incentivos económicos como recompensas y propinas. Para Biffi, estas desviaciones sobre la conciencia ambiental del programa se entienden por el fuerte componente burocrático basado en el sistema público de rendición de cuentas que las comunidades hacen al Estado.

Grace Palacios también parte del análisis del PNCB, en este caso de la participación de tres comunidades kichwa. La autora plantea una caracterización de esta participación a partir del tipo de involucramiento y cantidad de participantes en la ejecución de este mecanismo de transferencias condicionadas, identificando factores que facilitan y limitan el actuar de grupos minoritarios - en el sentido de quienes acceden a menos oportunidades - dentro de las comunidades, resaltando la dimensión de género en estas dinámicas.

Anahí Chaparro plantea un ejercicio de antropología simétrica al comparar dos redes — no desconectadas entre sí- que implican distintas formas de conocer: la de las relaciones que constituyen el territorio de «San Martín, región verde» y 
la de las relaciones de crianza de los kichwa, partiendo de una comunidad de los alrededores de Lamas. El interés de la autora es aproximarse a los vínculos que este conocer activa a través de sus efectos, a sus modos de constituir sujetos y de producir el territorio. Por un lado, aborda el entrelazamiento entre humanos, plantas, animales y otros seres que comparten el mismo entorno, desde la perspectiva kichwa, como sujetos con agencia y voluntad propia que conforman una red de cuidados, no exenta de tensiones. Por el otro, considera cómo los actores que participan en la conservación de la «región verde» conciben el territorio al exteriorizarlo y estriarlo en mapas que definen fronteras en el espacio y entre lo legal y lo ilegal, así como cuestionan la condición de las comunidades nativas en tanto sujetos de derecho. La autora enfatiza cómo ambas implican diferentes nociones de cuidado, que podrían nutrirse mutuamente si se abrieran a la posibilidad de verse afectadas.

Miguel Valderrama explora los vínculos entre los kichwa de la comunidad nativa Callanayaku, en el Bajo Huallaga, con la mina de sal del mismo nombre, a partir de lo que dicen sobre su aprovechamiento en el pasado. En los relatos sobre la historia de esta mina se resaltan interacciones entre los kichwa de Callanayaku con personas foráneas (empleados de una empresa de recaudación de impuestos, indígenas de otros pueblos, comerciantes, personal de salud) a través de la circulación de la sal, en especial el intercambio comercial. La disponibilidad de la sal para todos estos grupos, según el autor, es explicada por las personas en la comunidad a través del control sobre las relaciones sociales en las redes de comercio y la distribución de la sal.

Laura Volpi reflexiona sobre la relación entre la ciencia genética y el discurso sobre ancestralidad en la política indígena - en el contexto de un conflicto por el establecimiento de un área de conservación regional - frente a otros modos de relación entre los vivos y los ancestros. Este artículo examina los malentendidos existentes sobre los conceptos de «ascendencia» y «territorio», cuyo significado, en el ámbito indígena, supera los límites impuestos por la jurisdicción nacional y la terminología jurídica. De hecho, a pesar de haber asimilado un discurso genético-ancestral, varios líderes indígenas hoy lo van remodelando a la luz de una concepción nativa del territorio, concebido como una compleja red de relaciones, presentes y activas entre los seres humanos vivos y los ancestros.

Michelle Hak Hepburn aborda las implicancias de concebir el conocimiento indígena sobre aspectos ecológicos como conocimiento colectivo regido por la legislación de propiedad intelectual (Ley 27811). Para la autora, mientras que la ley representa un acercamiento legal avanzado para poder abordar 
las desigualdades de poder, sigue siendo problemática. No aborda el empobrecimiento de la población indígena y continúa subordinando los conocimientos ecológicos tradicionales a la ciencia cartesiana. Según Hak Hepburn, aunque sí representa un reconocimiento simbólico del valor de los pueblos indígenas peruanos, aún son necesarios otros mecanismos para poder compensar la larga historia de colonización y racismo.

El conjunto de textos que acabamos de reseñar deja entrever distintos caminos para pensar el territorio, en particular el que habitan los kichwa de la región San Martín: como escenario de dinámicas sociales, como objeto de políticas públicas, adjetivado como enfoque de gestión, como conjunto de recursos naturales que son objeto de conocimiento de las ciencias y de intercambio, como derecho indígena y como entramado de relaciones afectivas entre humanos y otros seres. Estos diferentes sentidos, a veces, coexisten en las experiencias de los distintos actores y permiten iluminar diferentes matices de las relaciones entre ellos, aunque no todos se incorporan en las formas de gobernanza. Esperamos que juntar las reflexiones de estas distintas perspectivas incentive a imaginar posibles diálogos entre ellas. 